\title{
PENILAIAN KERUSAKAN PADA GEDUNG KANTOR JASA RAHARJA LHOKSEUMAWE
}

\author{
Yulius Rief Alkhaly \\ Jurusan Teknik Sipil, Fakultas Teknik, Universitas Malikussaleh \\ email:yr.alkhaly@gmail.com
}

\begin{abstract}
Abstrak
Gedung kantor PT. Jasa Raharja (persero) Perwakilan Lhokseumawe berada di Jalan Malikussaleh No. 1, Kecamatan Banda Sakti, Lancang Garam, Kota Lhokseumawe. Gedung berlantai satu ini diperkirakan berumur 15 tahun (dibangun sekitar tahun 1997) dan diresmikan pemakaiannya pada 12 Agustus 1998. Kondisi eksisting elemen beton pada bangunan telah mengalami kerusakan berupa korosi tulangan dan retak, serta penurunan kualitas material dengan tingkat kerusakan yang bervariasi. Perbaikan diperlukan untuk mengembalikan masa layan bangunan agar dapat berfungsi secara aman dan nyaman. Pertimbangan utama perbaikan pada sistem struktur adalah kemudahan pengerjaan dan efisiensi biaya. Tahapan yang ditempuh dalam metode penelitian ini berupa: investigasi visual lapangan, penilaian tingkat kerusakan bangunan, evaluasi dan penentuan solusi. Evaluasi mutu beton dilakukan dengan alat Schmids Hammer dan Ultrasonic Pulse Velocity (UPV) pada elemen eksisting bangunan. Perbaikan bangunan dilakukan dengan mengunakan dua metode, pertama: seluruh elemen beton yang berkriteria rusak berat digantikan dengan elemen beton baru, kedua: elemen beton yang berkriteria rusak ringan/sedang dibobok lokal dan diganti beton baru. Dari hasil pengujian non-destruktif diketahui bahwa sisa kekuatan elemen beton diperkirakan sebesar $11 \mathrm{MPa}$, sehingga perlu tindakan penggantian struktur atap dengan konstruksi yang lebih ringan agar beban yang diterima oleh kolom menjadi lebih kecil.
\end{abstract}

Kata kunci: evaluasi mutu beton, tingkat kerusakan, perbaikan.

\section{Pendahuluan}

Gedung kantor PT. Jasa Raharja (persero) Perwakilan Lhokseumawe terletak di Jalan Malikussaleh No. 1, Lancang Garam, Kecamatan Banda Sakti, Kota Lhokseumawe, merupakan sarana bagi terlaksananya proses pelayanan jasa asuransi bagi pendukduk kota Lhokseumawe dan sekitarnya. Ketersedian sarana yang laik pakai akan memberikan tingkat kenyamanan dan keamanan bagi pegawai/karyawan dalam bekerja sehingga upaya memberikan pelayanan perkantoran yang lebih baik sesuai dengan motto Perusahaan: Utama dalam Perlindungan, Prima Dalam Pelayanan dapat terwujud.

Struktur gedung menggunakan balok dan kolom beton bertulang dengan dinding bata merah. Dilihat secara umum, pada gedung ini telah tampak retakan, korosi tulangan dan pelapukan pada beton strukturalnya, walaupun secara usia bangunan relatif masih muda, diperkirakan berumur 15 tahun (dibangun sekitar tahun 1997). Bangunan ini diresmikan pemakaiannya pada tahun 1998. Berhubung tidak adanya dokumen teknis pelaksanaan pembangunan berupa As built drawing dan dokumen pendukung lainnya (seperti data mutu bahan, rencana kerja dan syara-syarat), maka data awal yang digunakan adalah berdasarkan investigasi visual saja 


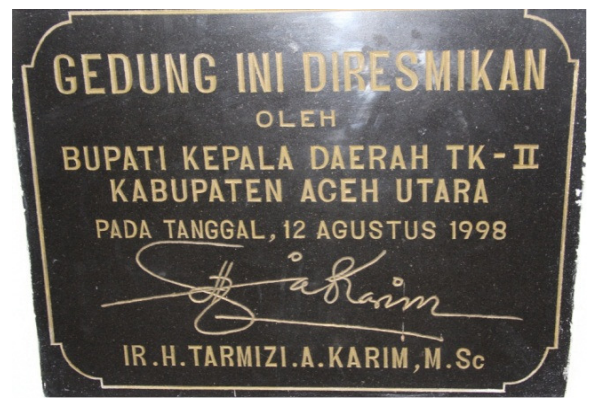

\section{Gambar 1 Plakat peresmian gedung kantor PT. Jasa Raharja (persero) Perwakilan Lhokseumawe}

Gedung ini merupakan bangunan 1 (satu) lantai, dengan luas lantai total sebesar $450 \mathrm{~m}^{2}$. Gaya arsitektur yang ditampilkan berupa gaya arsitektur rumah adat Aceh. Struktur utama gedung adalah kolom beton betulang diameter $40 \mathrm{~cm}$ dengan ketinggian $\pm 7 \mathrm{~m}$ sebanyak 20 buah. Pada dasar kolom terdapat pondasi tapak yang diperkirakan berukuran $1 \mathrm{~m} \mathrm{x} 1 \mathrm{~m}$. Pondasi tapak diikat oleh balok sloof dengan perkiraan ukuran $30 \mathrm{~cm}$ x $60 \mathrm{~cm}$. Pada ketinggian $4 \mathrm{~m}$, kolom utama dihubungkan oleh balok sun wearing berukuran $10 \mathrm{~cm} \times 65 \mathrm{~cm}$, dan pada ujung kolom atas mendukung ring balok berukuran $15 \mathrm{~cm} \times 22 \mathrm{~cm}$. Lantai bagian dalam ruangan dilapisi keramik $20 \mathrm{~cm}$ x $20 \mathrm{~cm}$ dan dinaungi oleh plafon papan kayu. Sebagai penutup atap, bangunan ini menggunakan genting yang disokong oleh kuda-kuda kayu bentang lebar. Bagian depan bangunan memiliki entrance yang disokong oleh kolom dengan diameter $40 \mathrm{~cm}$ sebanyak 2 buah dan kolom $40 \mathrm{~cm} \mathrm{x}$ $40 \mathrm{~cm}$ sebanyak 2 buah.

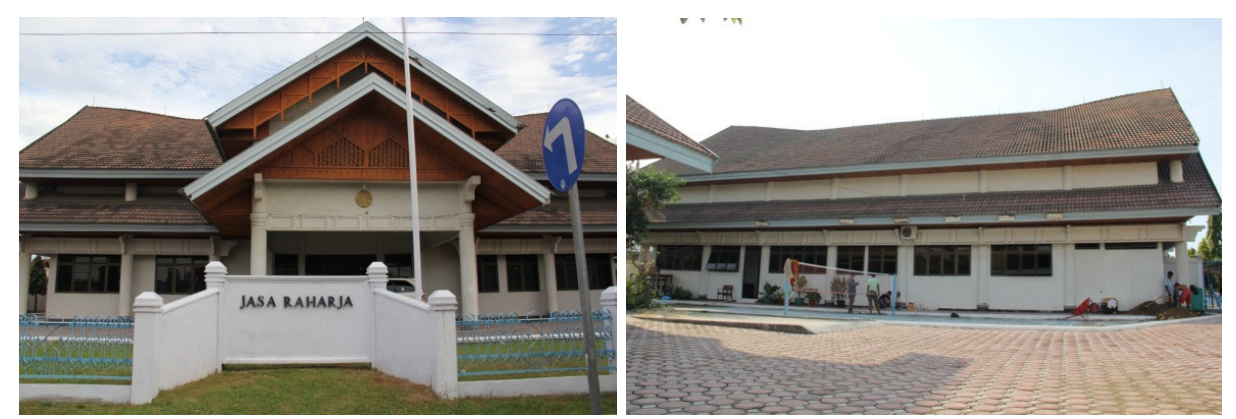

Gambar 2 Tampak depan dan belakang gedung kantor PT. Jasa Raharja (persero) Perwakilan Lhokseumawe

Lokasi pendirian bangunan awalnya merupakan daerah rawa-rawa dengan jenis tanah berpasir yang kemudian ditinggikan memakai timbunan tanah liat didatangkan dari lokasi lain. Gedung berjarak $\pm 1 \mathrm{~km}$ dari pantai. Dari jenis lokasi dan jaraknya yang cukup dekat ke laut, maka dapat pastikan bahwa lokasi bangunan merupakan daerah dengan lingkungan cukup moderat bagi terjadinya proses korosi.

Berdasarkan uraian di atas dan melihat kondisi struktur gedung saat ini, maka dalam upaya meminimalkan resiko kegagalan struktur dan konsekuensinya, perlu segera diketahui penyebab terjadinya korosi dan kerusakan lainnya sehingga diketahui pula cara perbaikan/perawatan yang tepat terhadap permasalahan yang terjadi. 


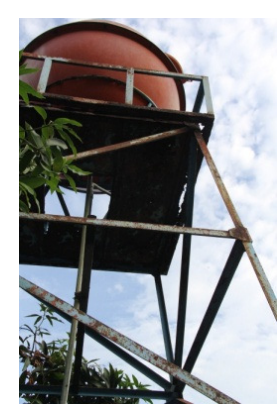

(a)

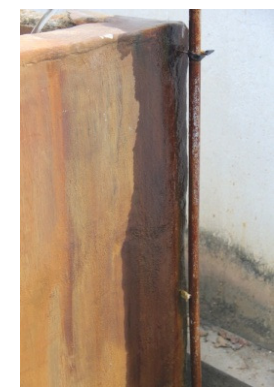

(b)

Gambar 3 (a) Korosi yang terjadi pada menara air. (b) Bercak karat pada bak air disebabkan oleh kondisi air rawa

Masa layan suatu bangunan gedung sangat dipengaruhi oleh ada-tidaknya kerusakan pada gedung pada gedung tersebut karena kinerja komponen struktur bangunan akan menurun bila adanya kerusakan. Langkah investigasi visual untuk memulai proses identifikasi tingkat kerusakan bangunan. Investigasi ini berguna untuk mendapatkan informasi awal tentang jenis kerusakan dan lokasinya. Selanjutnya data ini dipakai sebagai dasar dalam menentukan langkah identifikasi teknis dan alat pengujian yang tepat bagi pemeriksaan kerusakan (Anonim, 1996).

Agar tercapainya umur bangunan sesuai dengan umur rencana, maka diperlukan pemeliharaan dan perawatan bangunan secara berkala. Hal ini sejalan dengan definisi dan pengertian yang terdapat dalam Peraturan Menteri Pekerjaan Umum Nomor: 24/Prt/M/2008, tentang pedoman Pemeliharaan dan Perawatan Bangunan Gedung, yaitu:

a. Pemeliharaan bangunan gedung adalah kegiatan menjaga keandalan bangunan gedung beserta prasarana dan sarananya agar bangunan gedung selalu laik fungsi (preventive maintenance).

b. Perawatan bangunan gedung adalah kegiatan memperbaiki dan/atau mengganti bagian bangunan gedung, komponen, bahan bangunan, dan/atau prasarana dan sarana agar bangunan gedung tetap laik fungsi (currative maintenance).

\section{Dasar Teori}

\subsection{Pengujian Beton Tanpa Merusak (Non Destructive Test)}

\section{A. Hammer test}

Hammer test merupakan salah satu dari non distructive test sangat cocok bila dipakai untuk melakukan evaluasi keseragaman dari mutu beton. Alat ini mengandalkan besarnya nilai pantulan yang diberikan oleh permukaan beton yang dihammer. Semakin keras permukaan beton yang dihammer, semakin tinggi nilai reaksi dari pantulan (nilai rebound).

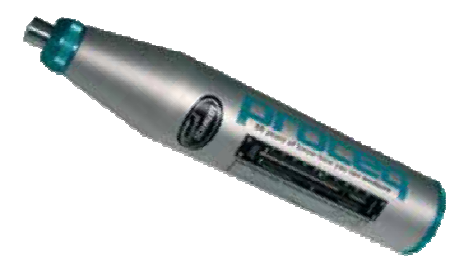

\section{Gambar 4 Schmids Hammer}

Penilaian KerusakanPada Gedung KantorJasa Raharja Lhokseumawe

- Yulius Rief Alkhaly 


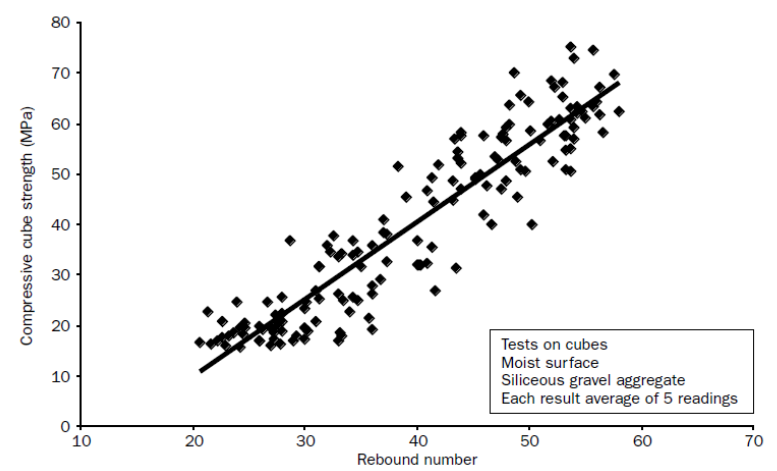

\section{Gambar 5 Hubungan Nilai Pantul dan Kuat Tekan Beton}

Sumber: Bungey, J. H., dan Millard, S. G., 1996

Harga rebound hammer diambil harga rata-ratanya dari 10 (sepuluh) pengujian. Selanjutnya harga ini diterjemahkan ke dalam nilai kuat tekan beton dan kriteria nilai pantul seperti diperlihatkan dalam Gambar 5 dan Tabel 1.

Tabel 1 Kriteria Penilaian Hasil Hammer Test

\begin{tabular}{|c|c|}
\hline Angka Pantulan Rata-rata & Kualitas Beton \\
\hline$>40$ & Sangat Baik \\
\hline $30-40$ & Cukup Baik \\
\hline $20-30$ & Kurang Baik \\
\hline$<20$ & Buruk \\
\hline
\end{tabular}

Sumber: Bungey, J. H., dan Millard, S.G., 1996

\section{B. Ultrasonik Pulse Velocity (UPV)}

Pengujian Ultrasonik berguna untuk mengetahui tingkat kepadatan beton dan kekuatan beton dengan mengkorelasikan hasil pengujian Ultrasonik dengan hasil kekuatan tekan.

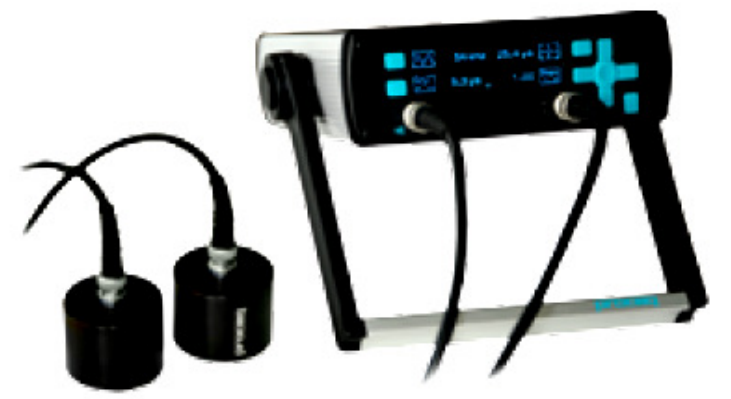

\section{Gambar 6 Alat Ultrasonic Pulse Velocity}

Hasil pengamatan dinyatakan dengan kecepatan rambat yang terjadi pada benda uji beton yang dites. Besar kecepatan ini berbanding lurus dengan kepadatan beton dan sekaligus juga berbanding lurus dengan kuat tekan beton tersebut. Hubungan nilai pantul dengan dengan nilai Pulse Velocity diperlihatkan dalam Gambar 7 berikut: 


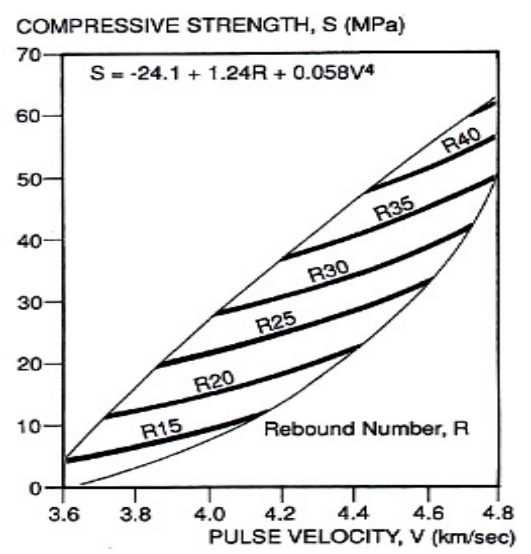

Gambar 7 Hubungan Nilai Pantulan dengan Pulse Velocity Sumber: Bungey, J. H., dan Millard, S.G., 1996

\subsection{Kriteria Penilaian Kerusakan}

Berdasarkan Peraturan Menteri Pekerjaan Umum Nomor: 24/Prt/M/2008 tentang Pedoman Pemeliharaan daan Perawatan Bangunan Gedung, kriteria tingkat kerusakan bangunan dapat digolongkan atas tiga tingkat kerusakan, yaitu:

a. Kerusakan ringan

1) Kerusakan ringan terutama pada komponen non-struktural, seperti penutup atap, langit-langit, penutup lantai, dan dinding pengisi.

2) Perawatan untuk tingkat kerusakan ringan, biayanya maksimum adalah sebesar $35 \%$ dari harga satuan tertinggi pembangunan bangunan gedung baru yang berlaku, untuk tipe/klas dan lokasi yang sama.

b. Kerusakan sedang

1) Kerusakan sedang adalah kerusakan pada sebagian komponen nonstruktural, dan atau komponen struktural seperti struktur atap, lantai, dan lain-lain.

2) Perawatan untuk tingkat kerusakan sedang, biayanya maksimum adalah sebesar $45 \%$ dari harga satuan tertinggi pembangunan bangunan gedung baru yang berlaku, untuk tipe/klas dan lokasi yang sama.

c. Kerusakan berat

1) Kerusakan berat adalah kerusakan pada sebagian besar komponen bangunan, baik struktural maupun non-struktural yang apabila setelah diperbaiki masih dapat berfungsi dengan baik sebagaimana mestinya.

2) Biayanya maksimum adalah sebesar $65 \%$ dari harga satuan tertinggi pembangunan bangunan gedung baru yang berlaku, untuk tipe/klas dan lokasi yang sama.

Sedangkan untuk keperluan penilaian, kriteria tingkat kerusakan didefinisikan sebagai berikut:

a. Kerusakan Ringan: yaitu elemen struktural atau non stuktural hanya mengalami kerusakan kecil (minor) yang tidak mempengaruhi kinerja secara struktur atau arsitektur.

b. Kerusakan Sedang: yaitu elemen struktural atau non stuktural telah mengalami kerusakan oleh deteriorasi minor, kehilangan luasan, pengelupasan, retak dan lainnya namun belum atau hanya sedikit mempengaruhi kinerja secara struktur atau arsitektur. 
c. Kerusakan Berat: yaitu elemen struktural atau non stuktural telah mengalami kerusakan oleh deteriorasi mayor, kehilangan luasan, pengelupasan, retak dan lainnya yang mempengaruhi kinerja secara struktur atau arsitektur.

\subsection{Jenis Kerusakan Beton dan Metode Perbaikan}

Dalam Tabel 2 berikut disajikan rangkuman berbagai metode perbaikan serta material yang dipakai untuk memperbaiki kerusakan pada beton bertulang.

Tabel 2 Jenis Kerusakan dan Metode Perbaikan

\begin{tabular}{|c|c|c|}
\hline Kerusakan & Metode Perbaikan & Material \\
\hline \multirow{5}{*}{$\begin{array}{l}\text { Retak yang } \\
\text { hidup } \\
\text { (Livelactive } \\
\text { crack) }\end{array}$} & - Caulking & Elastomeric Sealer \\
\hline & $\begin{array}{l}\text {-Injeksi bertekanan } \\
\text { menggunakan flexible filler }\end{array}$ & flexible epoxy filler \\
\hline & - Jacketing (strapping) & Kawat atau batang baja \\
\hline & - Overlaying & Membran atau mortar khusus \\
\hline & - Perkuatan & $\begin{array}{l}\text { Plat baja, post tensioning, } \\
\text { stitching,dsb }\end{array}$ \\
\hline \multirow[t]{10}{*}{$\begin{array}{l}\text { Retak yang } \\
\text { "dormant" }\end{array}$} & - Caulking & $\begin{array}{l}\text { Cement grout atau mortar, fast } \\
\text { setting mortar }\end{array}$ \\
\hline & $\begin{array}{l}\text {-Injeksi bertekanan } \\
\text { menggunakan rigid filler }\end{array}$ & rigid epoxy filler \\
\hline & - Coating & Bituminous coating, tar \\
\hline & - Overlaying & Asphalt overlay dengan membran \\
\hline & - Grinding dan overlaying & $\begin{array}{l}\text { Latex modified concrete, beton } \\
\text { sangat padat }\end{array}$ \\
\hline & - Dry pack & Dry pack \\
\hline & - Shotcrete & $\begin{array}{l}\text { Mortar(semen), fast setting mortar, } \\
\text { Mortar semen, beton epoxy atau } \\
\text { poyimer }\end{array}$ \\
\hline & - Jacketing (strapping) & Batang baja \\
\hline & - Perkuatan & post tensioning dsb \\
\hline & - Rekonstruksi & Sesuai kebutuhan \\
\hline - Voids & - Dry pack & - Dry pack \\
\hline \multirow[t]{5}{*}{-Honeycombs } & - Patching - & $P C$ grout, mortar atau semen \\
\hline & - Resurfacing & Beton epoxy atau polymer \\
\hline & - Shotcrete & Fast setting mortar \\
\hline & - Preplaced aggregate & Agregat kasar dan grout \\
\hline & - Penggantian & Sesuai kebutuhan \\
\hline \multirow[t]{4}{*}{ Scalling } & - Overlaying & $\begin{array}{l}\text { Beton, latex modified concrete, } \\
\text { semen aspal, epoxy atau polymer } \\
\text { concrete }\end{array}$ \\
\hline & - Shotcrete & Fast setting mortar, mortar semen \\
\hline & - Coating & Bituminous coating \\
\hline & - Penggantian & Sesuai kebutuhan \\
\hline \multirow[t]{5}{*}{ Spalling } & - Patching - & Beton epoxy, polymer, latex, aspal \\
\hline & - Shotcrete & mortar semen, Fast setting mortar \\
\hline & - Overlay & $\begin{array}{l}\text { latex modified concrete, beton aspal, } \\
\text { beton }\end{array}$ \\
\hline & - Coating & Bituminous coating \\
\hline & - Penggantian & Sesuai kebutuhan \\
\hline
\end{tabular}

Sumber: Isneini, M., 2009.

\section{Metodologi Penelitian}

\subsection{Investigasi Visual}

Kerusakan bangunan dapat disebabkan oleh banyak hal, seperti efek air, efek termal, efek pembebanan jangka panjang, efek beban siklik, efek kondisi lingkungan ekstrim, efek mutu material dan pengerjaan yang buruk, efek terkena bahan kimia berbahaya dan efek lainnya. Pemeriksaan berkala terhadap beton pada suatu kontruksi sangat diperlukan mengingat masa pelayanannya yang terus 
bertambah. Investigasi awal (preliminary investigation) atau investigasi visual (visual investigation) merupakan langkah awal dalam pemeriksaan bangunan eksisting. Investigasi inil bertujuan untuk memperoleh informasi awal tentang kondisi bangunan dan tingkat kerusakannya, kemungkinan perbaikan serta informasi tentang kebutuhan investigasi yang lebih jauh. Kondisi bangunan diamati secara visual dan dilakukan pengambilan gambar dengan menggunakan kamera digital. Bagian-bagian struktur bangunan yang mengalami kerusakan diamati dan difoto. Pengamatan dilakukan dengan tujuan untuk mengetahui tingkat kerusakan dan memutuskan kebutuhan investigasi detail yang bersifat teknis dan penentuan jenis alat pengujian. Langkah investigasi visual adalah:

1. Melakukan pengamatan atau pemeriksaan secara visual terhadap bagian-bagian bangunan yang mengalami gejala kerusakan atau kerusakan yang telah terjadi dan mencatat jenis kerusakan, tingkat kerusakan dan pola kerusakan.

2. Mengelompokkan bagian-bagian dari bangunan tersebut berdasarkan bagian yang rusak dan yang tidak rusak, kemudian menandai bagian yang rusak untuk dilakukan pemeriksaan nantinya.

3. Membuat sketsa bagian-bagian dari bangunan yang rusak, melakukan pemotretan dan mendeskripsikan jenis kerusakannya.

4. Menetapkan metode pemeriksaan yang perlu dilakukan nantinya dengan melihat kondisi dan situasi dari daerah yang mengalami kerusakan.

Alat yang dipakai dalam investigasi ini adalah: sikat baja, alat pengukur/meteran dan kamera digital.

\subsection{Investigasi Detail}

Tahap selanjutnya dalam melakukan identifikasi kerusakan adalah pelaksanaan Investigasi lengkap (detailed investigation). Kegiatan ini merupakan investigasi yang bersifat teknis. Kegiatan ini meliputi:

1. Dokumentasi

Pembuatan gambar teknis: denah, potongan, dan perkiraan pondasi.

2. Observasi kondisi lapangan

Hal-hal yang harus diidentifikasi antara lain:

a. Lebar, panjang, dan kedalaman retak, baik pada bagian struktural maupun nonstruktural, lokasi dan jenis retak;

b. Pengelupasan (spalling), retakan (cracking), Rongga (honeycombing), dan kerusakan pada permukaan lainnya turut dicatat dan direkam;

c. Korosi pada tulangan, ukuran awal dan ukuran setelah korosi.

3. Pengujian Lapangan

Pengujian nondestructive di lapangan untuk mengetahui kekuatan beton.

a. Pembobokan elemen beton;

b. Pengujian Schmids Hammer

Kekerasan beton atau kekuatan beton diuji dengan menggunakan alat yang diciptakan oleh Ernest Schmids, populer dengan nama Schmids Concrete Hammer;

c. Pengujian Ultrasonic Pulse Velocity

Pengujian kerapatan massa beton diuji dengan alat uji ultrasonik (UPV).

Pengujian dapat dilakukan dengan metoda langsung/tidak langsung. 
4. Interpretasi.

Tahap interpretasi dapat dibagi menjadi tiga tahapan yang berbeda :

a. Peninjauan mengenai kekuatan bahan.

b. Kalibrasi

c. Analisa/Perhitungan.

Alat yang dipakai dalam investigasi ini adalah: sikat baja, alat pengukur/meteran, martil, gerinda, kamera digital, Schmids Hammer tipe N 34, No 127023. dan Ultrasonic Pulse Velocity merek Pundit.

\section{Hasil dan Pembahasan}

\subsection{Lokasi dan Jenis Kerusakan}

Lokasi kerusakan elemen bangunan hasil investigasi dibuat berdasarkan lokasi grid dari denah lantai seperti ditunjukkan pada Gambar 8. Adapun jenisjenis dan tingkat kerusakan yang telah terjadi disajikan dalam bentuk tabulasi seperti diperlihatkan pada Tabel 3 dan Tabel 4. Kerusakan yang terjadi dikelompokkan menjadi dua bagian, yaitu:

1. Kerusakan bersifat struktural, yaitu kerusakan yang menurunkan daya tahan struktur dalam melayani beban bangunan dan dapat menyebabkan kegagalan struktur.

2. Kerusakan yang bersifat non struktural, yaitu kerusakan yang terjadi pada elemen arsitektur atau elemen bantu lainnnya yang tidak berdampak pada kegagalan struktur.

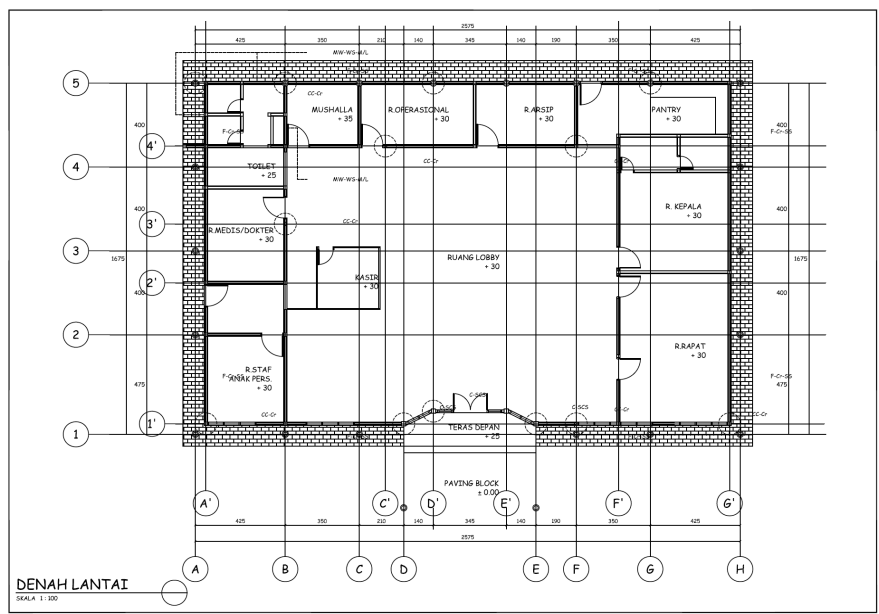

Gambar 8 Denah Lantai dan Grid-nya

Tabel 3 Jenis dan Lokasi Kerusakan Struktural

\begin{tabular}{|c|c|c|c|c|c|c|c|c|}
\hline No & Elemen & $\begin{array}{c}\text { Posi } \\
\text { si } \\
\text { Grid }\end{array}$ & $\begin{array}{c}\text { Ukuran } \\
\text { Elemen } \\
(\mathrm{cm})\end{array}$ & $\begin{array}{c}\text { Tulan- } \\
\text { gan }\end{array}$ & $\begin{array}{c}\text { Tebal } \\
\text { Seli- } \\
\text { mut } \\
(\mathrm{cm})\end{array}$ & $\begin{array}{c}\text { Jenis } \\
\text { keusa- } \\
\text { kan }\end{array}$ & Penyebab & $\begin{array}{c}\text { Tingkat } \\
\text { Kerusa-kan }\end{array}$ \\
\hline 1 & 2 & 3 & 4 & 5 & 6 & 7 & 8 & 9 \\
\hline 1 & $\begin{array}{c}\text { Kolom } \\
\text { praktis }\end{array}$ & $\mathrm{A}-1$ & $13 \times 13$ & $4 \varnothing 10$ & $\begin{array}{c}1,5 \\
\mathrm{~cm}\end{array}$ & Retak & $\begin{array}{c}\text { Pergerakan lateral } \\
\text { dinding (gempa), } \\
\text { dan degradasi } \\
\text { mutu beton }\end{array}$ & Sedang \\
\hline
\end{tabular}


Lanjutan Tabel 3

\begin{tabular}{|c|c|c|c|c|c|c|c|c|}
\hline 1 & 2 & 3 & 4 & 5 & 6 & 7 & 8 & 9 \\
\hline 2 & $\begin{array}{l}\text { Kolom } \\
\text { praktis }\end{array}$ & C-1 & $13 \times 13$ & $4 \varnothing 10$ & $\begin{array}{l}1,5 \\
\mathrm{~cm}\end{array}$ & $\begin{array}{l}\text { Retak } \\
\text { memen- } \\
\text { jang }\end{array}$ & $\begin{array}{c}\text { Pengaruh lendutan } \\
\text { balok yang } \\
\text { menumpu di } \\
\text { atasnya }\end{array}$ & Berat \\
\hline 3 & Kolom & D-1 & $33 \times 65$ & $6 \varnothing 14$ & 4 & $\begin{array}{l}\text { Retak, } \\
\text { Pengelup } \\
\text { asan }+ \\
\text { Korosi } \\
\text { tulangan }\end{array}$ & $\begin{array}{c}\text { Korosi karena } \\
\text { degradasi mutu } \\
\text { beton, sisa dia. tul. } \\
12 \mathrm{~mm}\end{array}$ & Berat \\
\hline 4 & Kolom & $D^{\prime}-1$ & $33 \times 65$ & $6 \varnothing 14$ & 4 & $\begin{array}{c}\text { Retak } \\
\text { sambung } \\
\text { an, Korosi } \\
\text { tulangan } \\
\end{array}$ & $\begin{array}{c}\text { Korosi karena } \\
\text { degradasi mutu } \\
\text { beton, sisa dia. tul. } \\
13 \mathrm{~mm}\end{array}$ & Berat \\
\hline 5 & Kolom & $E^{\prime}-1$ & $33 \times 65$ & $6 \varnothing 14$ & 4 & $\begin{array}{c}\text { Retak } \\
\text { sambu- } \\
\text { ngan }\end{array}$ & $\begin{array}{c}\text { Kurang baik } \\
\text { rekatan antara } \\
\text { permukaan kolom } \\
\text { lama dengan } \\
\text { plesteran baru }\end{array}$ & Ringan \\
\hline 6 & $\begin{array}{l}\text { Kolom } \\
\text { praktis }\end{array}$ & $F-1$ & $13 \times 13$ & $4 \varnothing 10$ & 1,5 & Retak & $\begin{array}{c}\text { Korosi karena } \\
\text { degradasi mutu } \\
\text { beton, sisa dia. tul. } \\
9 \mathrm{~mm}\end{array}$ & Berat \\
\hline 7 & $\begin{array}{l}\text { Kolom } \\
\text { praktis }\end{array}$ & $\mathrm{H}-1$ & $13 \times 13$ & $4 \varnothing 10$ & 1,5 & $\begin{array}{l}\text { Pengelup } \\
\text { asan dan } \\
\text { Korosi } \\
\text { tulangan } \\
\end{array}$ & $\begin{array}{c}\text { Korosi karena } \\
\text { degradasi mutu } \\
\text { beton, sisa dia. tul. } \\
7 \mathrm{~mm}\end{array}$ & Berat \\
\hline 8 & $\begin{array}{l}\text { Kolom } \\
\text { praktis }\end{array}$ & B-3' & $13 \times 13$ & $4 \varnothing 10$ & 1,5 & $\begin{array}{l}\text { Pengelup } \\
\text { asan dan } \\
\text { Korosi } \\
\text { tulangan }\end{array}$ & $\begin{array}{c}\text { Korosi karena } \\
\text { degradasi mutu } \\
\text { beton, sisa dia. tul. } \\
7 \mathrm{~mm}\end{array}$ & Berat \\
\hline 9 & $\begin{array}{l}\text { Kolom } \\
\text { praktis }\end{array}$ & $C-4^{\prime}$ & $13 \times 13$ & $4 \varnothing 10$ & 1,5 & $\begin{array}{l}\text { Retak } \\
\text { meman- } \\
\text { jang }\end{array}$ & $\begin{array}{c}\text { Korosi tulangan } \\
\text { dan pengaruh } \\
\text { lendutan balok } \\
\text { yang menumpu di } \\
\text { atasnya }\end{array}$ & Berat \\
\hline 10 & $\begin{array}{l}\text { Kolom } \\
\text { praktis }\end{array}$ & $\mathrm{F}-4^{\prime}$ & $13 \times 13$ & $4 \varnothing 10$ & 1,5 & $\begin{array}{l}\text { Retak dan } \\
\text { Korosi } \\
\text { tulangan }\end{array}$ & $\begin{array}{l}\text { Korosi tulangan } \\
\text { dan pengaruh } \\
\text { lendutan balok } \\
\text { yang menumpu di } \\
\text { atasnya, sisa dia. } \\
\text { tul. } 7 \mathrm{~mm} \\
\end{array}$ & Berat \\
\hline 11 & Balok & $\begin{array}{l}\text { As-C } \\
\text { dan } \\
\text { As-F }\end{array}$ & $\begin{array}{c}21 \times 25, \\
\text { Panjang } \\
: 1800\end{array}$ & $4 \varnothing 12$ & $\begin{array}{l}1,5 \\
\mathrm{~cm}\end{array}$ & $\begin{array}{c}\text { Defleksi } \\
\text { besar, } \delta= \\
14,9 \mathrm{~cm}\end{array}$ & $\begin{array}{l}\text { Ukuran balok dan } \\
\text { tulangan terpasang } \\
\text { tidak sesuai } \\
\text { dengan panjang } \\
\text { bentang balok }\end{array}$ & Berat \\
\hline 12 & $\begin{array}{l}\text { Balok } \\
\text { sun } \\
\text { wea- } \\
\text { ring }\end{array}$ & $\begin{array}{l}\text { Kelil } \\
\text { ing } \\
\text { ge- } \\
\text { dun } \\
\text { g }\end{array}$ & $\begin{array}{c}10 \times 64, \\
\text { Panjang } \\
: \text { variasi } \\
3100 \text { s.d } \\
4000\end{array}$ & $\begin{array}{l}2 \varnothing 8 \\
\text { (tulan } \\
\text { gan } \\
\text { bawa } \\
\text { h) }\end{array}$ & 4 & $\begin{array}{c}\text { Retak, } \\
\text { lebar } \\
\text { retak } \\
\text { variasi } 1 \\
\text { mm s.d } 2 \\
\text { mm }\end{array}$ & $\begin{array}{c}\text { Tulangan } \\
\text { terpasang tidak } \\
\text { sesuai beban } \\
\text { sendiri balok }\end{array}$ & Sedang \\
\hline
\end{tabular}

Penilaian KerusakanPada Gedung KantorJasa Raharja Lhokseumawe 
Lanjutan Tabel 3

\begin{tabular}{|c|c|c|c|c|c|c|c|c|}
\hline 1 & 2 & 3 & 4 & 5 & 6 & 7 & 8 & 9 \\
\hline 13 & Balok & $\begin{array}{c}\text { entr } \\
\text { anc } \\
\text { e }\end{array}$ & $\begin{array}{c}20 \times 60, \\
\text { Panjang } \\
: 6250\end{array}$ & - & - & $\begin{array}{c}\text { Retak, } \\
\text { lebar } \\
\text { retak } \\
\text { variasi } 1 \\
\text { mm s.d } 2 \\
\text { mm }\end{array}$ & $\begin{array}{c}\text { Retak pada } \\
\text { sambungan balok- } \\
\text { kolom disebabkan } \\
\text { oleh pergerakan } \\
\text { lateral (gempa), } \\
\text { sedangkan retak pada } \\
\text { bagian tengah } \\
\text { bentang balok dapat } \\
\text { diduga akibat } \\
\text { tulangan yang } \\
\text { terpasang kurang dari } \\
\text { semestinya }\end{array}$ & Sedang \\
\hline
\end{tabular}

Tabel 4 Jenis dan Lokasi Kerusakan Non-Struktural

\begin{tabular}{|c|c|c|c|c|}
\hline No & Elemen & $\begin{array}{c}\text { Jenis } \\
\text { Kerusakan }\end{array}$ & $\begin{array}{c}\text { Tingkat } \\
\text { Kerusakan }\end{array}$ \\
\hline 1 & $\begin{array}{c}\text { Lantai } \\
\text { Selasar }\end{array}$ & $\begin{array}{c}\text { Retak, lebar } \\
\text { retak variasi 1 } \\
\text { mm s.d 3 mm }\end{array}$ & $\begin{array}{c}\text { Retak karena pengaruh thermal, selanjutnya } \\
\text { terjadi rembesan air di bawah lantai yang } \\
\text { mengakibatkan pergeseran/penurunan tanah }\end{array}$ & Sedang \\
\hline 2 & Dinding & $\begin{array}{c}\text { Rembesan air } \\
\text { dan berlumut }\end{array}$ & $\begin{array}{c}\text { Rembesan air disebabkan oleh pasangan bata } \\
\text { dan plesteran tidak kedap air }\end{array}$ & Berat \\
\hline 3 & $\begin{array}{c}\text { Plafon } \\
\text { Luar }\end{array}$ & $\begin{array}{c}\text { Pelapukan } \\
\text { kayu }\end{array}$ & $\begin{array}{c}\text { Rembesan air yang mengakibatkan pelapukan } \\
\text { papan kayu karena jenis kayu yang tidak } \\
\text { tahan terhadap perubahan basah-kering }\end{array}$ & Berat \\
\hline Listplank & $\begin{array}{c}\text { Pelapukan } \\
\text { kayu }\end{array}$ & $\begin{array}{c}\text { Pelapukan papan kayu oleh pergantian basah } \\
\text { kering, jenis kayu yang digunakan tidak tahan } \\
\text { terhadap keadaan tersebut }\end{array}$ & Berat \\
\hline
\end{tabular}

\subsection{Interpretasi Hasil Pengujian}

\subsubsection{Pengujian Pembobokan}

Pengujian Pembobokan dimaksudkan untuk memperoleh gambaran terhadap kemudahan/kesukaran dalam menghancurkan matriks beton. Dari hasil pembobokan ini dapat diketahui beberapa keadaan, yaitu:
a. Warna matriks beton;
b. Ukuran agregat;
c. Kelekatan agregat;
d. Diameter dan kondisi tulangan beton, serta
e. Tebal selimut beton.

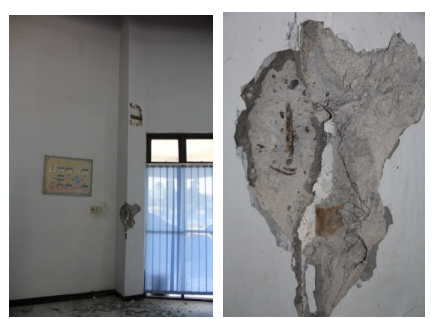

(a)

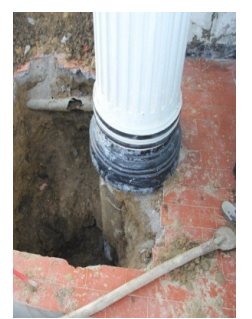

(b)

Gambar 9 (a) Pembobokan pada Kolom E'-1 (kondisi rusak), (b) Pembobokan pada Pondasi Kolom A-5 (kondisi utuh) 
Selain pada elemen beton yang telah mengalami kerusakan, pembobokan juga dilakukan pada elemen beton yang kelihatan masih baik dan utuh. Hal ini dilakukan guna memperoleh data pembanding.

Selanjutnya untuk Interpretasi hasil pengujian pembobokan dapat dijelaskan sebagai berikut:

a. Warna matriks beton

Dari hasi pembobokan pada elemen beton kondisi rusak dan pembobokan pada elemen beton kondisi utuh, diketahui bahwa warna matriks beton dari seluruh elemen adalah putih pucat, hampir menyerupai warna dari Gambar 10(a). Hanya elemen yang terdapat pada elemen pondasi warna matriks betonnya menyerupai Gambar 10(b). Dengan demikian dapat diinterpretasikan bahwa:

- Tidak dilakukan perawatan elemen beton sebagaimana mestinya pada masa sesudah pengecoran, terlihat bahwa warna elemen beton pada pondasi lebih baik dikarenakan oleh terjaganya kehilangan air semen.

- Faktor air semen (FAS) yang digunakan diperkirakan berkisar antara 0,6 0,8; seharusnya untuk daerah dengan kondisi lingkungan moderat FAS minimum adalah 0,5 .

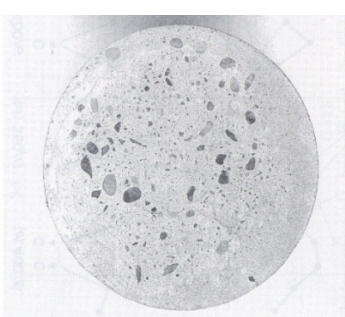

(a)

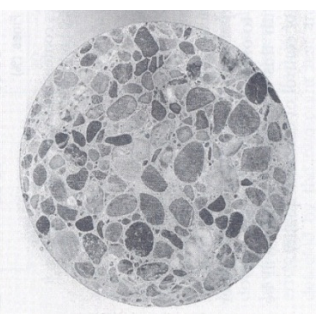

(b)

Gambar 10 (a) Beton dengan Faktor Air Semen 0,65; dan

(b) Beton dengan Faktor Air Semen 0,5 Sumber: Popovics, S., 1992

b. Ukuran agregat;

Gambar 11 memperlihatkan ukuran agregat maksimum yang didapat dari hasil pembobokan pada elemen kolom D-1 dan kolom E'-1. Ukuran agregat maksimum mencapai $70 \mathrm{~mm}$, padahal standar ukuran maksimum yang diperbolehkan untuk beton struktural adalah $40 \mathrm{~mm}$. Dengan demikian dapat diinterpretasikan bahwa: Agregat yang digunakan tidak memenuhi syarat uji saringan

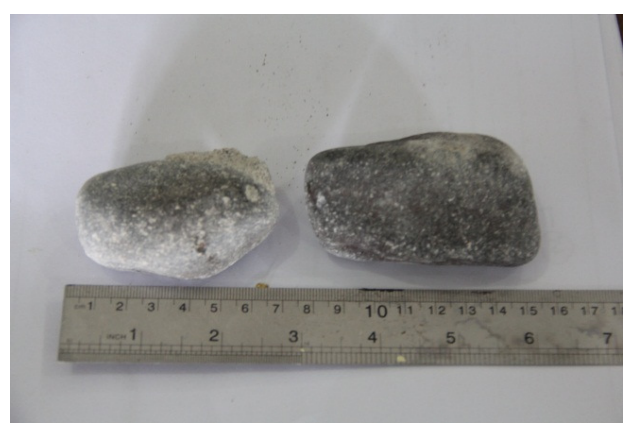

Gambar 11 Ukuran Agregat Maksimum yang Digunakan

Penilaian KerusakanPada Gedung KantorJasa Raharja Lhokseumawe 
c. Kelekatan agregat

Pada elemen kondisi rusak maupun pada elemen kondisi utuh, kelekatan agregat kasar dengan semen sangat lemah dan diketahui bahwa kekuatan selimut beton lebih baik dibanding inti elemen. Pada sebagian elemen beton agregat kasar dapat dicabut menggunakan tangan, hanya pada elemen pondasi yang memiliki kelekatan agregat yang baik. Selanjutnya, diketahui pula bahwa seluruh elemen kondisi rusak tidak dapat diratakan permukaannya menggunakan gerinda karena agregat kasar langsung terlepas. Berdasarkan hal ini dapat diinterpretasikan bahwa: Mutu awal beton rendah, dan diperkirakan pengadukan beton menggunakan air payau (air di lokasi gedung), sehingga pada umur 15 tahun beton telah mengalami gradasi mutu (penurunan mutu) secara bertahap akibat reaksi bahan-bahan di dalam semen dengan air payau.

d. Diameter dan keadaan tulangan beton

Elemen kolom diameter $40 \mathrm{~cm}$ dan kolom $33 \mathrm{~cm}$ x $65 \mathrm{~cm}$, menggunakan tulangan diameter $14 \mathrm{~mm}$. Elemen kolom praktis dan elemen ring balok menggunakan diameter tulangan $10 \mathrm{~mm}$. Kondisi tulangan beton pada elemen beton kondisi rusak, sedangkan pada elemen kondisi utuh, keadaan tulangan relatif masih baik walau telah tampak korosi ringan, kecuali pada elemen kolom B-5 terlihat tulangan sudah mulai korosi. Hal ini terjadi karena elemen kolom B-5 terletak di daerah kelembaban tinggi (kamar mandi). Berbeda dengan elemen kolom lainnya, kondisi tulangan beton masih baik (tanpa korosi) ditemui pada elemen pondasi kolom A-5.

e. Tebal selimut beton

Tebal selimut beton yang di dapat dari hasil pengukuran adalah sebagai berikut:

- Elemen kolom bulat dan kolom persegi $4-5 \mathrm{~cm}$

- Elemen kolom praktis dan ring balok 1,5 - $2 \mathrm{~cm}$

\subsubsection{Pengujian Schmids Hammer} berikut:

Hasil pengujian menggunakan alat Schmids Hammer disajikan dalam tabel

Tabel 5 Nilai Pantulan Schmids Hammer pada Elemen Beton Kondisi Utuh

\begin{tabular}{|c|c|c|c|}
\hline No. & Elemen Beton & Rata-Rata Nilai Pantul & Kualitas Beton \\
\hline 1 & Kolom B-5 & 38 & Cukup \\
\hline 2 & Kolom D'-5 & 32 & Cukup \\
\hline 3 & Kolom G-5 & 17 & Buruk \\
\hline 4 & Ring Balok As 4-GH & 21 & Kurang Baik \\
\hline & Rata-rata total (R) & 27 & Kurang Baik \\
\hline
\end{tabular}

Berdasarkan grafik dari Gambar 5, diperkirakan bahwa nilai kuat tekan ratarata beton pada elemen yang telah mengalami kerusakan adalah sebesar $11 \mathrm{MPa}$, sedangkan perkiraan nilai kuat tekan rata-rata beton pada elemen yang tampak baik adalah $20 \mathrm{MPa}$. Jadi, seleuruh elemen beton yang telah mengalami kerusakan dapat dipastikan telah terjadi degradasi mutu beton. 
Tabel 6 Nilai Pantulan Schmids Hammer pada Elemen Beton Kondisi Rusak

\begin{tabular}{|c|c|c|c|}
\hline No. & Elemen Beton & Rata-Rata Nilai Pantul & Kualitas Beton \\
\hline 1 & Kolom Praktis A-1 & 20 & Kurang Baik \\
\hline 2 & Kolom Persegi D1 & 19 & Buruk \\
\hline 3 & Kolom Persegi D'-1 & 14 & Buruk \\
\hline 4 & Kolom Persegi E'-1 & 21 & Kurang Baik \\
\hline 5 & Kolom Praktis H-1 & 16 & Buruk \\
\hline 6 & Kolom Praktis B-3' & 28 & Kurang Baik \\
\hline 7 & Kolom Praktis F-4' & 18 & Buruk \\
\hline & Rata-rata total (R) & 20 & Kurang Baik \\
\hline
\end{tabular}

\subsubsection{Pengujian Ultrasonic Pulse Velocity (UPV)}

Berhubung permukaan beton yang telah mengalami kerusakan tidak dapat dilakukan perataan, maka pengujian dengan UPV tidak dapat dilaksanakan langsung pada permukaan beton. Dalam hal ini, pengujian UPV hanya dilakukan terhadap 3 (tiga) sampel potongan matriks beton yang diambil dari Kolom E-1. Ketebalan sampel adalah $6 \mathrm{~cm}$. Dari hasil pengujian UPV di dapat nilai Pulse Velocity-nya rata-rata adalah $3551 \mathrm{~m} / \mathrm{s}$ atau mendekati $3,6 \mathrm{~km} / \mathrm{s}$. Berdasarkan nilai rata-rata pantulan pada elemen beton kondisi rusak $(\mathrm{R}=20)$, dan nilai Pulse Velocity $=3,6 \mathrm{~km} / \mathrm{s}$, maka berdasarkan grafik pada Gambar 7 didapat perkiraan kuat tekan beton adalah sebesar $11 \mathrm{MPa}$.

\subsubsection{Perbaikan Kerusakan}

Kekuatan beton pada elemen struktur dengan tingkat kerusakan berat telah mengalami degradasi mutu, yaitu kuat tekan sisa mendekati $11 \mathrm{MPa}$. Berdasarkan hal ini, maka langkah terbaik dalam perbaikan elemen beton dengan kriteria rusak berat adalah mengganti dengan elemen beton yang baru. Sedangkan untuk elemen dengan kondisi rusak sedang cukup dilakukan pembokokan lokal pada area yang mengalami kerusakan, kemudian diganti dengan massa beton baru dengan mutu beton $>20 \mathrm{MPa}$. Agar masa layan gedung dapat diperpanjang, maka struktur atap bangunan ini sebaiknya diganti dengan struktur yang lebih ringan, hal ini dimaksudkan agar beban yang dilimpahkan ke struktur di bawahnya akan lebih kecil.

\section{Kesimpulan dan Rekomendasi}

\subsection{Kesimpulan}

Berikut adalah beberapa kesimpulan yang dihasilkan invetigasi awal, investigasi lengkap dan interpretasi hasil pengujian, yaitu:

1. Gedung kantor PT. Jasa Raharja (persero) Perwakilan Lhokseumawe telah mengalami kerusakan pada elemen struktural dan non struktural dengan tingkat kerusakan yang bervariasi, yaitu kerusakan ringan, kerusakan sedang, sampai kerusakan berat;

2. Kerusakan elemen beton pada gedung disebabkan oleh mutu beton yang rendah, sehingga terjadinya penestrasi agen-agen perusak beton (air, karbon dioksida dan oksigen).

3. Lendutan balok pada As $\mathrm{C}$ dan As F sudah melawati ambang batas lendutan, hal ini disebakan oleh ukuran penampang balok yang tidak sesuai dengan panjang bentangnnya. 
4. Kondisi bekas rawa tempat berdirinya gedung turut mempengaruhi laju kerusakan, terutama terhadap korosi tulangan beton.

\subsection{Rekomendasi}

Guna memperpanjang masa layanan pemakaian gedung kantor PT. Jasa

Raharja (persero) Perwakilan Lhokseumawe, diajukan beberapa rekomendasi:

1. Bersifat segera, sebelum dilakukan renovasi: Menopang atau memberi sokongan pada balok As C dan balok As F dengan menggunakan perancah kayu atau perancah besi untuk menghindari runtuhnya balok-balok tersebut.

2. Menggantikan struktur atap yang semula dari konstruksi kayu menjadi konstruksi baja ringan, serta mengganti penutup atap dari genting beton menjadi genting metal, hal ini dimaksudkan untuk memperingan struktur sehingga beban yang diterima oleh kolom menjadi lebih kecil;

3. Membongkar balok-balok pada As C dan As F, bila memungkinkan pada bagian tersebut ditambah dinding pemisah ruangan, hal ini dimaksudkan untuk memperkuat dan menyatukan kedudukan dinding-dinding luar;

4. Menggantikan seluruh elemen beton yang berkriteria rusak berat dengan elemen beton baru;

5. Mengganti plasteran dinding pada bagian yang mengalami rembesan air dengan plesteran baru beradukan $1: 2$ dan melapisinya dengan material water proofing.

6. Agar pekerjaan renovasi memiliki rencana kerja dan syarat-syarat yang jelas, maka perlu dilakukan pekerjaan desain lanjutan, yaitu "Detailed Enginering Design" terhadap pekerjaan struktur, arsitektur dan mekanikal/elektrikal.

\section{Daftar Kepustakaan}

1. Anonim, 1996, Guide to Concrete Repair, United State Department of Interior Bureau of Reclamation, Technical Service Center

2. Anonim, 2008, Peraturan Menteri Pekerjaan Umum Nomor: 24/Prt/M/2008 tentang Pedoman Pemeliharaan dan Perawatan Bangunan Gedung;

3. Bungey, J. H., dan Millard, S. G., 1996, Testing of Concrete in Structure, Blackie Academic \& Professional, An Imprint Of Chapman \& Hall, London

4. Isneini. M., 2009, Kerusakan dan Perkuatan Struktur Beton Bertulang, Jurnal Rekayasa Vol. 13 No. 3

5. Popovics, S., 1992, Concrete Materials: Properties, Specifications and Testing. 2nd edition, Noyes Publications, New Jersey. 